\title{
Complete Description of Forces Acting on a Flying Beach Volleyball
}

\author{
Jan Dumek ${ }^{1 *}$, Pavel Šafař́k ${ }^{1}$, \\ ${ }^{1}$ Department of Fluid Dynamics and Thermodynamics, Faculty of Mechanical Engeneering, Czech Technical University in \\ Prague, Technická 4, 190 00, Czech Republic
}

\begin{abstract}
Complete description of all forces acting on a flying Beach Volleyball was made based on measurements in the wind tunnel. Forces (drag, lift and side force) were measured for different angle of attack $\beta$ which varies from $0^{\circ}$ to $47^{\circ}$. Velocity region was from 10 to $25 \mathrm{~m} / \mathrm{s}$ and revolution region was from 0 to 12.5 rps. Moments (Roll, Yaw, Pitch) were detected. Results are described by means of non-dimensional numbers, such as Reynolds number Re, spin s, drag $C_{D}$, lift $C_{L}$ and side force $C_{S}$ coefficients. Differences in results of $C_{D}, C_{L}$ and $C_{S}$ were detected for various angle $\beta$ and are further described in the article. Conclusions of the investigation can be utilized $1^{\text {st }}$ by ball producers for practical use in development, $2^{\text {nd }}$ for sport Methodist to build more exact methodology for Beach Volleyball, $3^{\text {rd }}$ in basic and applied aerodynamic research.
\end{abstract}

\section{Introduction}

Forces acting on rotating sport ball (as well as any other body in flow) which is in the wind tunnel test section are three, drag force $F_{D}$, lift force $F_{L}$ and side force $F_{S}$. Three moments are acting on balls in the flow in a nonsymmetric case of flow "Roll" $M_{X}$, "Yaw" $M_{Y}$, "Pitch" $\mathrm{Mz}$.

Experimental data of forces acting on the flying rotating sphere were measured in different studies and were published in articles [1], [2], [3], [4], [5] and others. Different approaches were used. Free observation of rotating spheres, which are thrown into water is one approach [1], second describes trajectory of flight of a volleyball in real conditions [4] and others [3] measured forces acting on the volleyball fixed in a special stand in an aerodynamic wind tunnel test section. Wind tunnel measurements can describe with forces acting (forces and moments) on a rotating sphere, therefore a right set-up is required.

The measurement set-up, which can measure all three components of force and all three components of moments, is described in next chapter, Description of Experiment. The results of the realized measurements are presented in the article.

\section{Description of Experiment}

The experiment was conducted in a $1.8 \mathrm{~m}$-diameter lowspeed wind tunnel in the laboratories of Aerospace Research and Test Establishment in Prague. The set-up principal is visible in Figure 2. Forces were measured by
6 dynamometers, two in direction of the lift force $\mathrm{F}_{\mathrm{L}}$, three in direction of the drag $F_{D}$ and one in direction of side force. Air-flowing velocities of $\mathrm{v}=<10-25>\mathrm{m} / \mathrm{s}$ were observed. Reynolds number of measurement is in the range of $1.5-3.8 \times 10^{5}$. The ball was rotating in these revolutions: $\mathrm{n}=<0,12.5>$ rps.

Non dimensional parameters such as Reynolds number $R e$ and the spin s are calculated according to the equations (1) and (2):

$$
\begin{aligned}
& R e=\frac{v d}{v}, \\
& s=\frac{\pi n d}{v},
\end{aligned}
$$

where $v$ is velocity $[\mathrm{m} / \mathrm{s}], \mathrm{d}$ is diameter of the ball [m], $v$ is kinematic viscosity $\left[\mathrm{m}^{2} / \mathrm{s}\right], \mathrm{n}$ is revolution [rps]. Spin is a nondimesional expression of movement in the boundary condition and in the fluid. Meanwhile Strouhal number is criterium of impulsive and inertial forces.Values of Reynolds number are shown tab. 1.

Table 1. - Reynolds number values

\begin{tabular}{|c|c|c|c|c|c|c|}
\hline $\begin{array}{c}\mathrm{V} \\
{[\mathrm{m} / \mathrm{s}]}\end{array}$ & 10 & 15 & 17 & 19 & 21 & 25 \\
\hline $\mathrm{Re}$ & 152 & 228 & 259 & 289 & 320 & 381 \\
{$[-]$} & 420 & 630 & 120 & 600 & 090 & 060 \\
\hline
\end{tabular}

The spin number is in the range $\mathrm{s}=(0-0.85)$.

Revolutions were conducted and measured by a "stepping motor" and in this article are conducted as a

* Coresponding author: jandumek@gmail.com 
independent value and recalculations of the spin number are not performed. All the values were recorded by the Labview program and evaluated afterwards by using a Matlab based program.

An experimental set-up is depicted in figures 1. and 2.

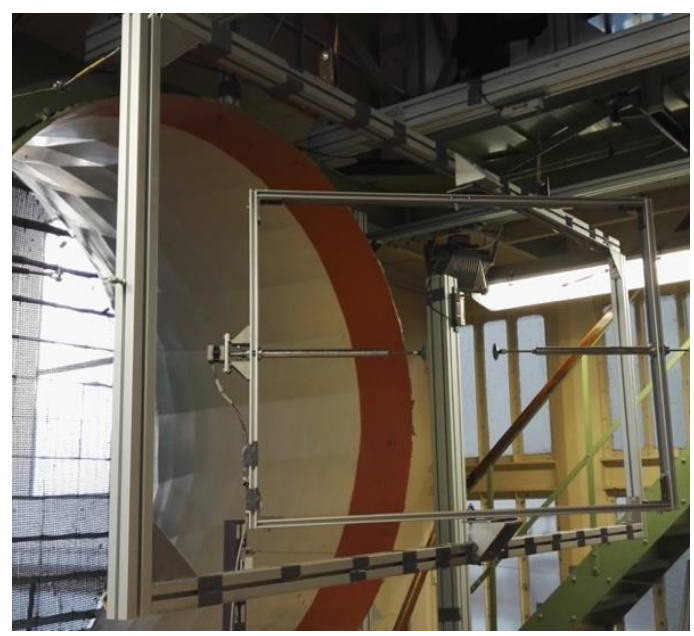

Fig. 1. Special stand for measurement of all 3 forces without volleyball

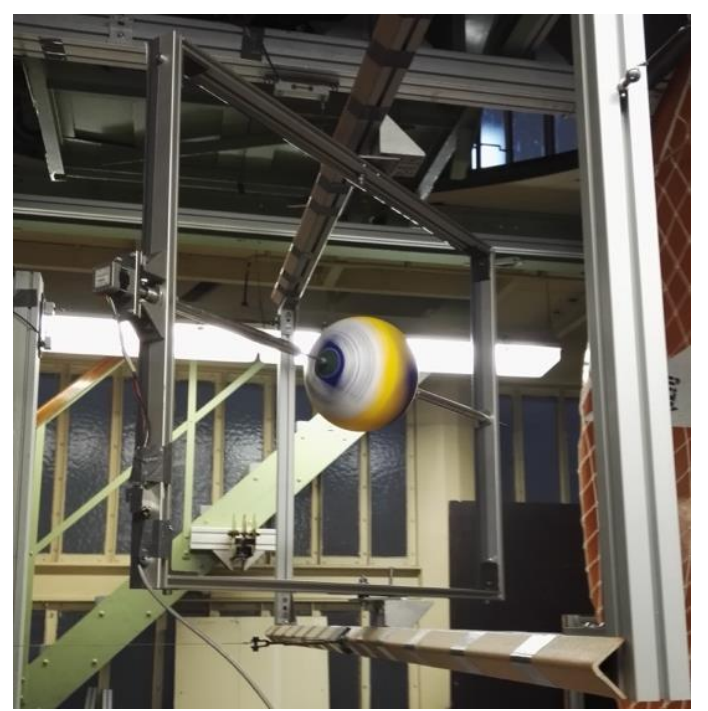

Fig. 2. Special stand for measurement of all 3 forces with rotating volleyball

Influence of moments and influence of side forces must be taken in consideration for a complete description of the situation. This experimental set up enable an observation by measurement of forces and moments acting on a rotating sphere in different angle of the airstream $-\beta$ : axis of a rotating ball is not just normal to the airstream, but has also a defined angle $\left(\beta=0-45^{\circ}\right)$.

Forces and moments are calculated according to the equations (3) - (8):

- Drag:

$$
F_{D}=F_{3}+F_{4}+F_{5}
$$

- Lift:

$$
F_{L}=F_{1}+F_{2}
$$

- $\quad$ Side force:

$$
F_{S}=F_{6}
$$

- Roll:

$$
M_{X}=F_{1} \cdot a-F_{2} \cdot a
$$

- Yaw:

$$
M_{Y}=F_{4} \cdot f-F_{3} \cdot f
$$

- Pitch:

$$
M_{Z}=\left(F_{3}+F_{4}\right) \cdot b-F_{5} \cdot c
$$

From kinematic scheme, which can be seen in Figure 3 , is defined in a complete picture of forces $\left(\mathrm{F}_{\mathrm{D}}, \mathrm{F}_{\mathrm{L}}, \mathrm{F}_{\mathrm{S}}\right)$ and torques $\left(\mathrm{M}_{\mathrm{X}}, \mathrm{M}_{\mathrm{Y}}, \mathrm{M}_{\mathrm{Z}}\right)$ acting on the rotating volleyball. Based on the kinematic scheme, the real stand and frame were constructed and installed in a wind tunnel test section, depicted in Figure 2. The measurement is prepared.

Forces acting on the special stand without volleyball were measured firstly and then charcteristics of the volleyball in the stand were measured in the same conditions ( $\mathrm{v}$ and $\mathrm{n}$ ) as in the experiment - in purpose to deduct influence of the stand. Volleyball characteristics: I. must be spherical, II. circumference is in the range of $650-670 \mathrm{~mm}$, III. weight of $260-280 \mathrm{~g}$, IV. internal pressure $0,300-0,325 \mathrm{~kg} / \mathrm{cm}^{2}$. The volleyball MIKASA VLS 300 was measured.

\section{Results}

Results of coefficients $C_{D}, C_{L}, C_{S}$ and moments $M_{X}, M_{Y}$, $\mathrm{M}_{\mathrm{Z}}$ are depicted at figures 4. -21 .

\section{Discussion}

Basic principles are observed in the figures of results:

1. Drag coefficient for $\beta=0^{\circ}$ (Fig. 4.). Dependence of Drag coefficient for $n=0$ rps shows that results include region of critical Reynolds number (according to theory critical Reynolds number smooth sphere $\mathrm{Re}_{\mathrm{CR}}=300$ 000, [6]). Drag coefficient firstly decreses to critical region and increases in turbulent region.

2. With increasing revolutions area of critical Re moves (Fig. 4.). Revolutions apparently have impact on drag force - increasing revolutions decrease the drag. This phenomena will be studied and described more detialed in further articles.

3. Lift coefficient increases with increasing revolutions, as in [7].

4. Influence of the rotation $\mathrm{n}$ and angle of attack $\beta$ is evident on each depandences.

5. Strict concept of symetry is not confirmed in the observation.

Theoreticaly lift force (coefficient $\mathrm{C}_{\mathrm{L}}$ ) should be equal to zero for $\mathrm{n}=0 \mathrm{rps}$. 


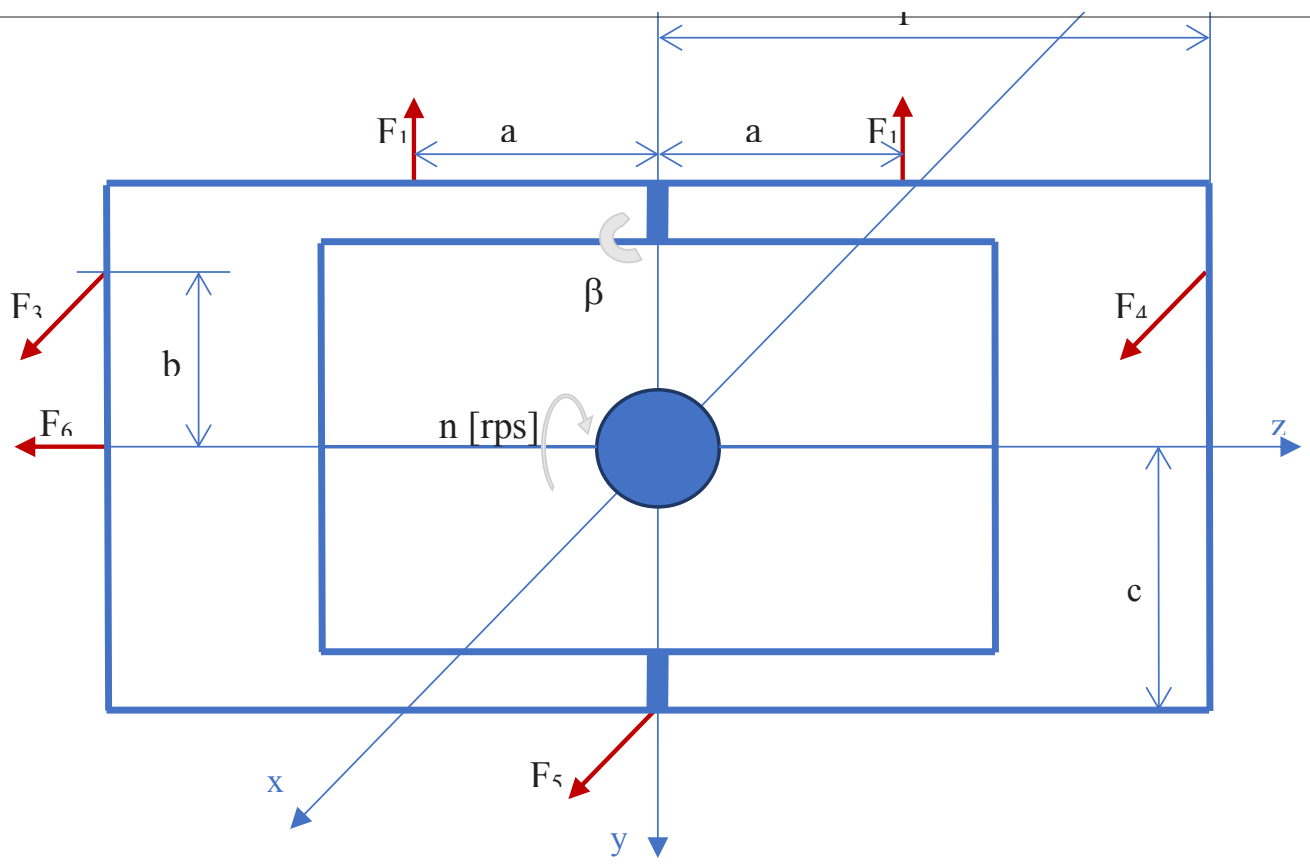

Fig. 3. Force scheme for the set-up

$$
\mathrm{C}_{\mathrm{D}} \beta=0^{\circ}
$$

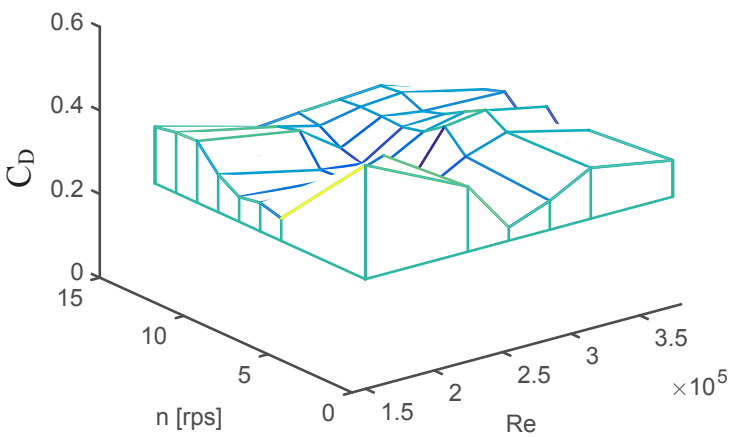

Fig. 4. Drag coefficient $C_{D} \beta=0^{\circ}$

$$
\mathrm{C}_{\mathrm{D}} \beta=47.08^{\circ}
$$

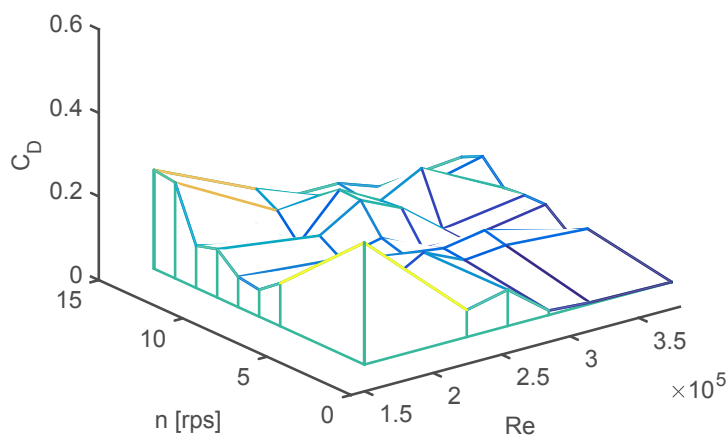

Fig. 5. Drag coefficient $C_{D} \beta=47.08^{\circ}$

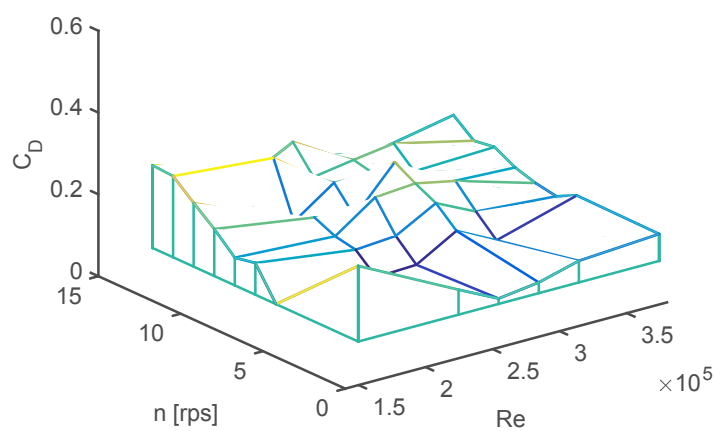

Fig. 6. Drag coefficient $C_{D} \beta=30.70^{\circ}$

$$
\mathrm{C}_{\mathrm{L}} \beta=0^{\circ}
$$

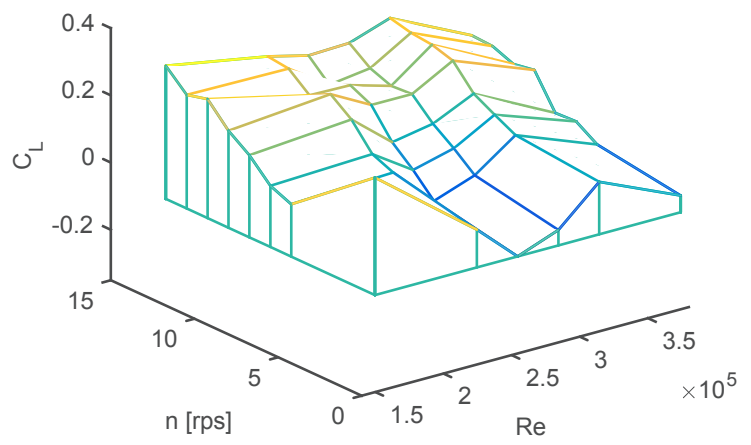

Fig. 7. Lift coefficient $C_{L} \beta=0^{\circ}$ 
$\mathrm{C}_{\mathrm{L}} \beta=30.70^{\circ}$

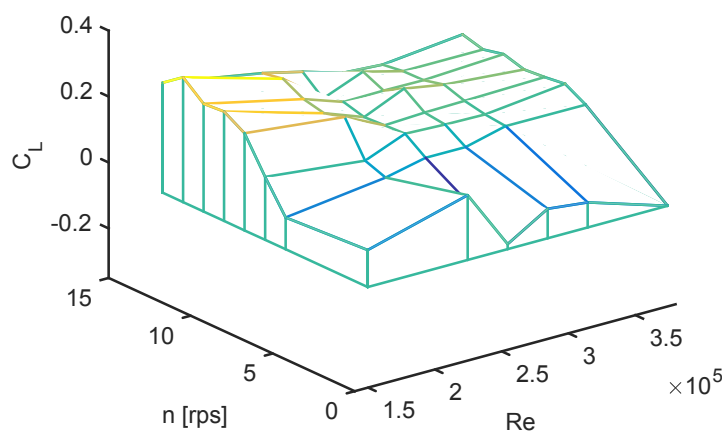

Fig. 8. Lift coefficient $C_{L} \beta=30.70^{\circ}$

$$
\mathrm{C}_{\mathrm{S}} \beta=0^{\circ}
$$

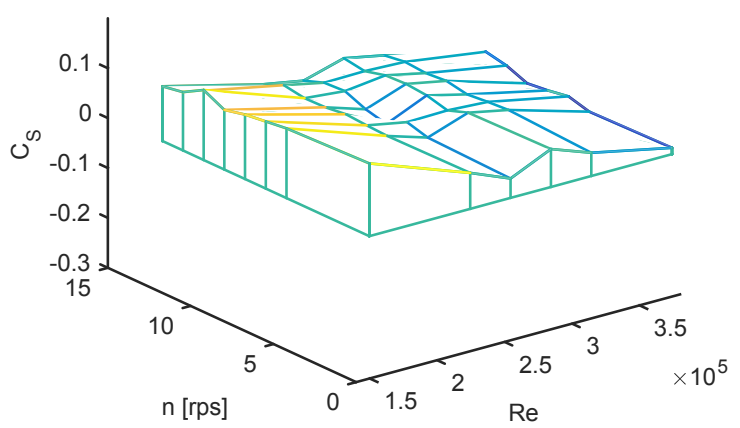

Fig. 9. Side force coefficient $C_{s} \beta=0^{\circ}$

$$
\mathrm{C}_{\mathrm{S}} \beta=47.08^{\circ}
$$

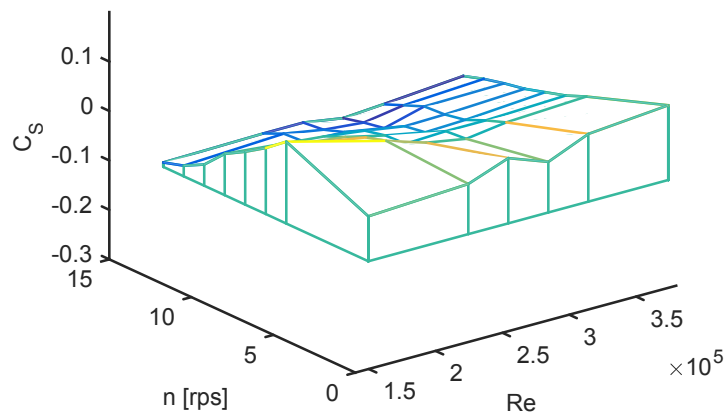

Fig. 10. Side force coefficient $C_{S} \beta=47.08^{\circ}$
$\mathrm{C}_{\mathrm{L}} \beta=47.08^{\circ}$

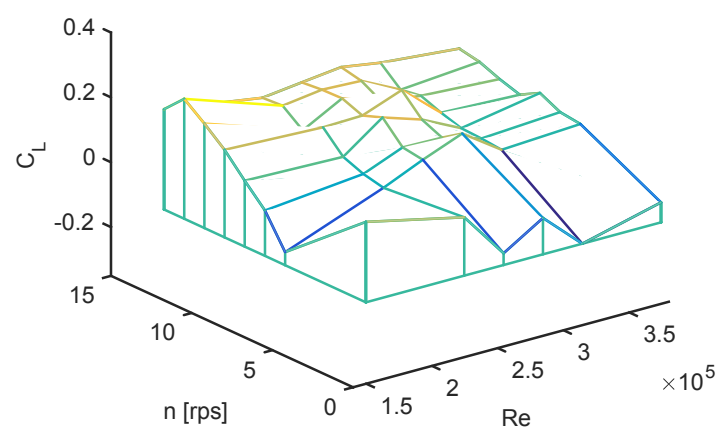

Fig. 11. Lift coefficient $C_{L} \beta=47.08^{\circ}$

$$
\mathrm{CS}_{\mathrm{S}} \beta=30.70^{\circ}
$$

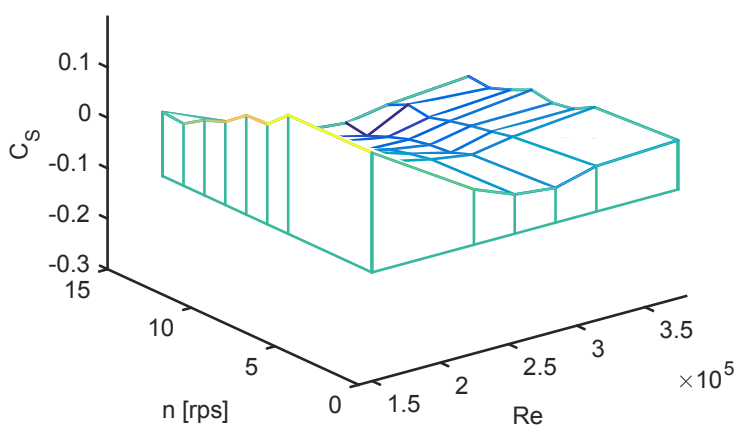

Fig. 12. Side force coefficient $C_{S} \beta=30.70^{\circ}$

$$
\mathrm{M}_{\mathrm{X}} \beta=0^{\circ}
$$

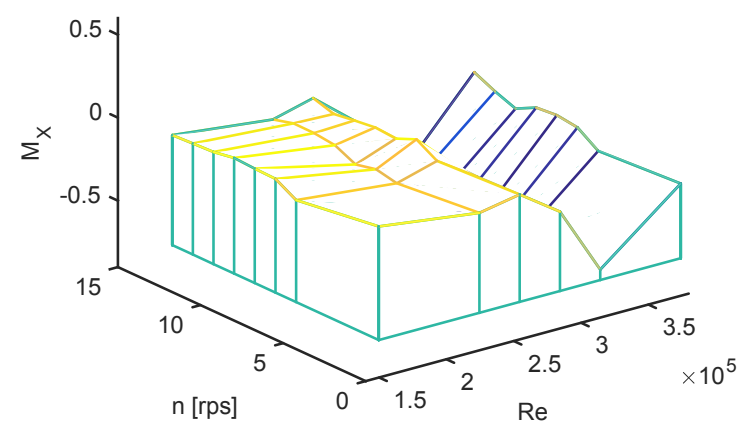

Fig. 13. Moment $M_{X} \beta=0^{\circ}$ 


$$
\mathrm{M}_{\mathrm{X}} \beta=30.70^{\circ}
$$

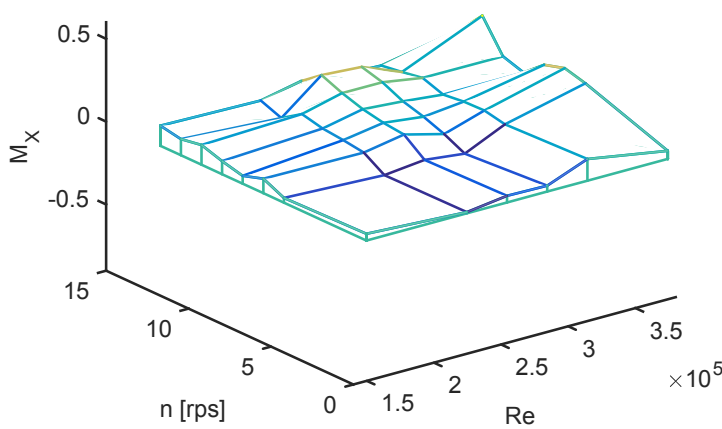

Fig. 14. Moment $M_{X} \beta=30.70^{\circ}$

$$
\mathrm{M}_{\mathrm{Y}} \beta=0^{\circ}
$$

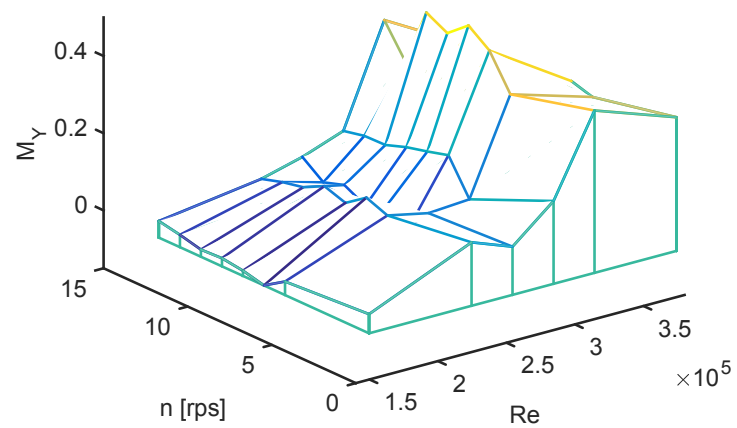

Fig. 15. Moment $M_{Y} \beta=0^{\circ}$

$$
\mathrm{M}_{\mathrm{Y}} \beta=47.08^{\circ}
$$

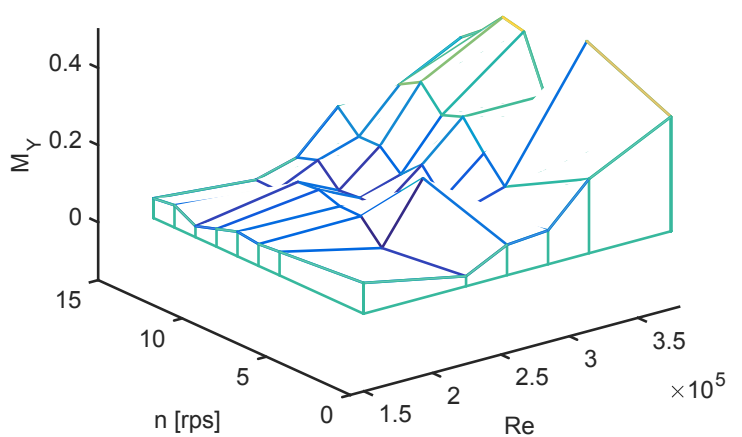

Fig. 16. Moment $M_{Y} \beta=47.08^{\circ}$
$\mathrm{Mx} \beta=47.08^{\circ}$

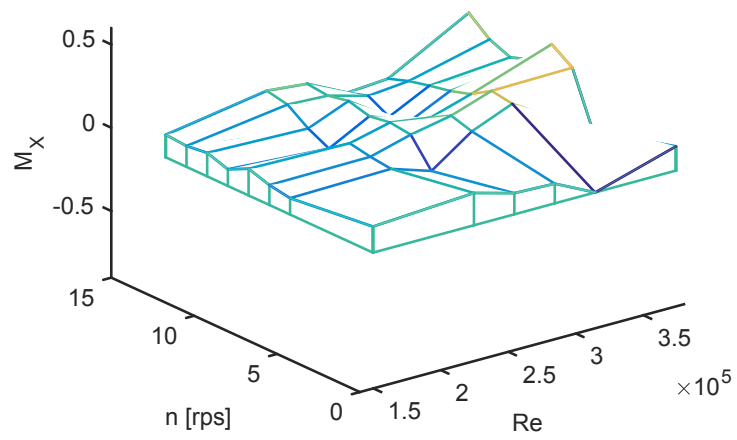

Fig. 17. Moment $M_{x} \beta=47.08^{\circ}$

$$
\mathrm{M}_{\mathrm{Y}} \beta=30.70^{\circ}
$$

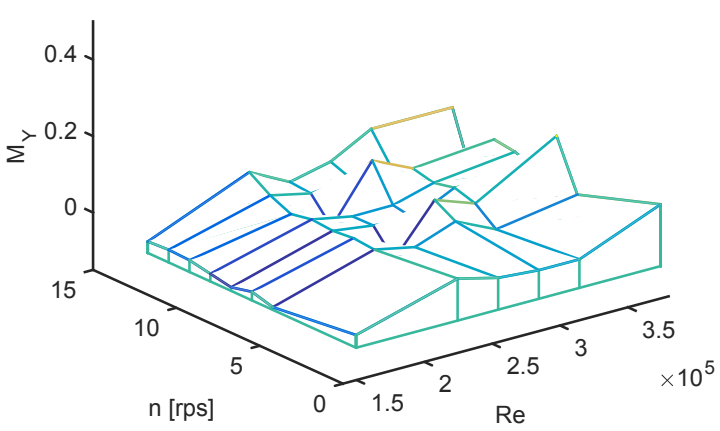

Fig. 18. Moment $M_{Y} \beta=30.70^{\circ}$

$$
\mathrm{M}_{\mathrm{Z}} \beta=0^{\circ}
$$

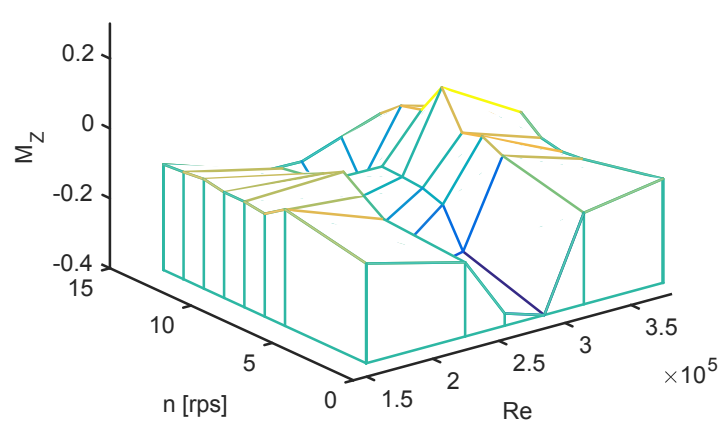

Fig. 19. Moment $M_{z} \beta=0^{\circ}$ 


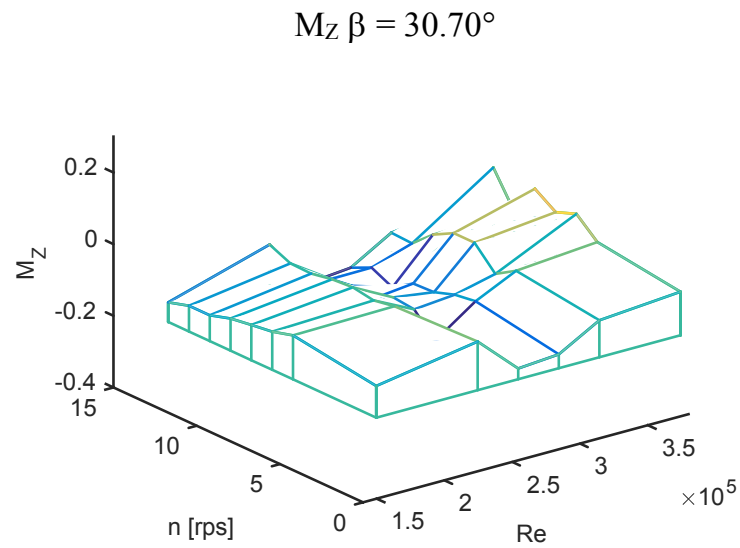

Fig. 20. Moment $M_{z} \beta=30.70^{\circ}$

\section{Conclusions}

Experimental set up of volleyball, which rotates in two planes in the wind tunnel was made and experiment was performed. Results are shown in the Section 3 Results. Basic principles, which are evident from results were described in the Section 4 Discussion. Results will be studied more thoroughly. Based on the principels described in Discussion, main conclusion is made:

1. detailed results study will be made,

2. measurement uncertainties must be counted and described,

3. moments coefficients will be counted and results will be described,

4. aerodynamic characteristic $C_{L}$ vs. $C_{D}$ will be described.

\section{Acknowledgments}

Support from from the Project No. CZ.2.16/3.1.00/21569 Centre 3D Volumetric Anemometry is gratefully acknowledged.

\section{References}

1. A. Kharlamov, Z. Chára, P. Vlasák: Experimental investigation of Magnus force acting on smooth sphere at high Reynolds numbers, Colloquium Fluid Dynamics 2008, Prague, (2008)

2. R. G. Watts, R. Ferrer: The lateral force on a spinning sphere: Aerodynamics of a Curvebal. Am. J. Phys., 55, 40-44, (1987)

3. T. Asaia, S. Itob, K. Seoc, A. Hitotsubashi: Aerodynamics of a new volleyball, Procedia Engineering 2 2493-2498, Elsevier, (2010)

4. R. D. Mehta: Aerodynamics of sport balls, Annual Rewiew of Fluid Mechanics, page 151 189, In: M. van Dyke, etal.: Annual Rewiews , Palo Alto, Vol. 17, (1985)

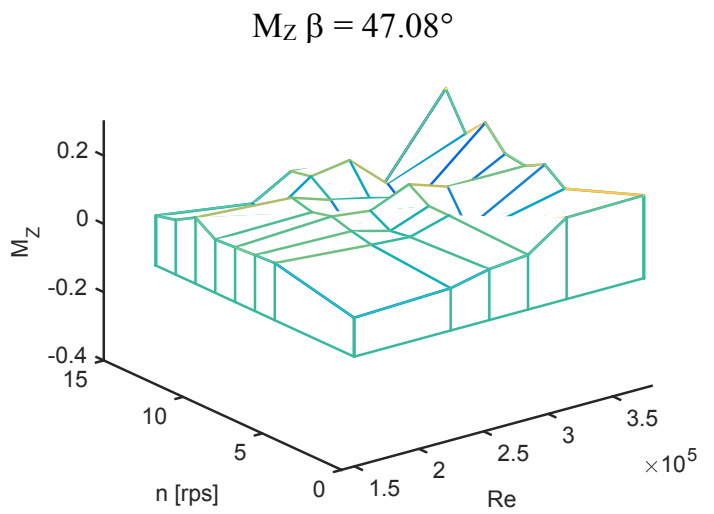

Fig. 21. Moment $M_{Z} \beta=47.08^{\circ}$

5. Wei Qing-Ding, Lin Rong-Sheng, Liu Zhi-Jin : Vortex-induced dynamic loads on a non-spinning volleyball, Fluid dynamics research, North Holland, 2000

6. R. W. Fox, A. T. McDonald, A.T.: Introduction to fluid mechanics, John Wiley \& Sons, New York, (1994)

7. Dumek, J., Šafařík, P.: Aerodynamic experimental tests of forces and torques acting on the volleyball, page 113 - 116 In: Šmurda, D., Bodnár, T.: Topical Problems of Fluid Mechanics 2017, Conference, Prague, (2017) 